\title{
KEEFEKTIFAN PENDIDIKAN KESEHATAN DENGAN METODE DEMONSTRASI TERHADAP KETERAMPILAN IBU DALAM PIJAT BAYI
}

\author{
Mia Rita Sari ${ }^{1)}$, Madinah $^{2)}$ \\ ${ }^{1,2}$ Program Studi Diploma Tiga, Akademi Kebidanan Husada Gemilang \\ Email: mia.ritasari@yahoo.com
}

\begin{abstract}
ABSTRAK
Pijat bayi merupakan salah satu bentuk fisioterapi yang berpengaruh positif terhadap proses tumbuh kembang balita selain pemberian makanan tambahan. Dari 10 orang ibu yang mempunyai balita $80 \%$ ibu mengatakan pernah melakukan pijat bayi saat sakit demam dengan membawanya ketukang pijat. Karena minimnya pengetahuan yang dimiliki oleh ibu, tenaga kesehatan dapat memberikan pendidikan kesehatan tentang pijat bayi dengan metode demonstrasi karena keterampilan seseorang dapat diasah melalui metode demonstrasi. Penelitian ini bertujuan untuk mengetahui keefektifan pendidikan kesehatan dengan metode demonstrasi terhadap keterampilan ibu dalam pijat bayi d iPosyandu Serai Wangi Wilayah Kerja Pustu Pekan Arba Tembilahan Kota. Desain penelitian adalah pre eksperimen, dengan pendekatan pre test dan post test tanpa kelompok kontrol, sampel sebanyak $21 \mathrm{ibu}$. Pengambilan sampel menggunakan teknik simple random sampling. Pengumpulan data melalui wawancara dan lembar cheklist. Analisis data menggunakan uji statistik t-test. Hasil penelitian didapatkan rata-rata keterampilan ibu dalam melakukan pijat bayi sebelum dan sesudah dilakukan pendidikan kesehatan dengan metode demonstrasi sebesar 54,67 dan 70,81. Berdasarkan hasil uji statistik pendidikan kesehatan dengan metode demonstrasi efektif terhadap peningkatan keterampilan ibu dalam melakukan pijat bayi $(0,000<0,05)$ sehingga diharapkan ibu mampu melakukan pijat bayi secara mandiri.
\end{abstract}

Kata Kunci: Pendidikan kesehatan, Keterampilan ibu, Pijat bayi

\section{ABSTRACT}

Baby massage is one form of physiotherapy that positively affects the growth process of toddlers in addition to supplementary feeding. There are still many parents who do not understand about baby massage, some think baby massage is done only on sick babies and by herbalists or medical personnel who master baby massage. Due to the lack of knowledge possessed by the mother, health workers can provide health education about baby massage by demonstration method because one's skills can be honed through demonstration method. This study aims to find out the effectiveness of health education by demonstration method of maternal skills in baby massage in Posyandu Serai Wangi Working Area Pustu Pekan Arba Tembilahan Kota. The design of the study was preexperimental, with a pre test and post test approach without a control group, a sample of 21 mothers. Sampling using simple random sampling technique. Data collection through interviews and cheklist sheets. Data analysis using t-test statistics. The results of the study obtained the average skills of mothers in performing baby massage before and after health education with demonstration methods of 54.67 and 70.81. Based on the results of statistical tests of health education with effective demonstration methods to improve the mother's skills in performing baby massage $(0.000<0.05)$ so that it is expected that the mother is able to perform baby massage independently.

Keywords: Health education, Mother's skills, Baby massage 


\section{PENDAHULUAN}

Tumbuh kembang bayi dan balita mengalami peningkatan yang pesat pada usia dini yaitu 0 sampai 5 tahun (golden age). Pada masa ini peran orang tua sangat berarti dan penting karena proses tumbuh kembang merupakan hasil interaksi faktor genetik dan lingkungan, untuk mengoptimalkan perkembangan potensi bawaan seorang anak dibutuhkan pengasuhan (asuh), kasih sayang (asih), dan stimulasi (asah) secara optimal (Marmi and Rahardjo, 2012).

Fisioterapi sangat besar perannya dalam membantu proses tumbuh kembang yang optimal, sehingga akan membentuk generasi yang berkualitas (Andriani, Merryana and Wijatmadi, 2012). Pijat bayi merupakan salah satu bentuk fisioterapi yang berpengaruh positif terhadap proses tumbuh kembang balita selain pemberian makanan tambahan. Pijat bayi sebagai bentuk stimulasi taktil yang diberikan oleh seseorang dimana terdapat manipulasi jaringan lunak sebagai sarana meningkatkan kesehatan dan kesejahteraan anak. Kontak taktil merupakan hal mendasar bagi perkembangan bayi baru lahir dan sebagai alat komunikasi antara bayi dan orang tuanya (Vicente, Veríssimo and Diniz, 2017)

Pijat bayi ini mempunyai pengaruh besar pada sistem peredaran darah dan sistem syaraf yang dapat menciptakan relaksasi pada tubuh sehingga pertumbuhan berat badan bayi diharapkan dapat meningkat, kuantitas tidur bayi dapat lebih lama, mengembangkan system imun dan ikatan kasih sayang antara orang tua dan bayi juga dapat terbentuk dengan adanya proses pijat bayi ini. Disamping itu pijat bayi juga tidak banyak memakan biaya, mudah, dan sudah turun temurun. Pijat bayi ini sangat baik untuk dilakukan mengingat masih banyak bayi di Indonesia yang memiliki masalah dengan berat badan maupun penyakit yang dialaminya (Roesli, 2015b).

Masih banyak orang tua yang belum mengerti tentang pijat bayi, sebagian dari mereka beranggapan bahwa pijat bayi dilakukan hanya pada bayi yang sakit serta dilakukan oleh dukun atau tenaga medis yang menguasai pijat bayi. Hal ini tidak sepenuhnya salah, melalui teknik tertentu, pijat bayi diyakini mampu mengatasi kolik sementara, sembelit dan bayi rewel. Namun, manfaat utama dari pijat bayi adalah membantu mengoptimalkan tumbuh kembang bayi. Dalam hal ini sangat diperlukan pendidikan kesehatan khususnya tentang pijat bayi diberikan oleh orangtua agar proses tumbuh kembang bayinya menjadi optimal (Rochmah, 2012).

Berdasarkan studi pendahuluan dengan metode wawancara pada 10 orang ibu yang mempunyai balita didapatkan hasil dari $80 \%$ ibu mengatakan pernah melakukan pijat bayi saat sakit demam dengan membawanya ketukang pijat atau dukun bayi karena belum ada klinik yang dibuka khususnya untuk melayani pijat bayi serta belum pernah mendapatkan pendidikan kesehatan tentang pijat bayi, kurang mengetahui manfaat pijat bayi dan belum mengetahui bagaimana cara memijat bayi yang benar sehingga tidak melakukan pijat bayi secara mandiri.

Keterampilan seseorang dapat ditentukan oleh pengetahuan, ketersediaan fasilitas dan perilaku petugas kesehatan sebagai fasilitator kesehatan. Manifestasi pengetahuan tidak dapat langsung dilihat, tetapi hanya dapat ditafsirkan terlebih dahulu dari perilaku tertutup. Pengetahuan secara nyata menunjukkan konotasi adanya kesesuaian reaksi terhadap stimulus tertentu dan didalam kehidupan sehari-hari sebagai reaksi yang bersifat emosional terhadap stimulus sosial (Notoatmodjo, 2012).

Hasil penelitian yang dilakukan (Handayani and Wulandari, 2021) didapatkan hasil bahwa ada pengaruh pendidikan kesehatan tentang pijat bayi terhadap pengetahuan ibu dengan hasil uji statistik didapatkan nilai $p$ adalah 0,0001 $(p<0,05)$. Penelitian yang dilakukan oleh (Sulistiani and Wijayanti, 2020) juga 
mengatakan terdapat perbedaan ketrampilan ibu dalam melakukan pijat bayi sebelum dan sesudah diberikan pendidikan kesehatan $(0,002<0,05)$.

Upaya yang dapat dilakukan untuk meningkatkan pengetahuan ibu tentang pijat bayi secara mandiri adalah dengan mendapatkan penyuluhan kesehatan tentang pijat bayi secara benar dan tepat. Peran bidan dalam hal ini sangat penting untuk memberikan penyuluhan. Dengan diberikan penyuluhan yang benar maka pengetahuan ibu akan bertambah dan dapat merubah sikap yang mendorong untuk bisa melakukan praktik pijat bayi secara mandiri (Ambasari, Anggarini and Nugraheni, 2017).

Salah satu cara agar informasi dapat diterima dan mudah dipahami oleh masyarakat khususnya pada ibu adalah melalui pendidikan kesehatan atau promosi kesehatan. Pendidikan kesehatan dapat menyampaikan informasi atau pesan kesehatan kepada masyarakat dengan metode pendekatan. Ada beberapa metode dalam menyampaikan pendidikan kesehatan salah satunya adalah melalui demonstrasi. Demonstrasi adalah metode pendidikan kesehatan yang memiliki kelebihan untuk meningkatkan proses pemahaman dan meningkatkan fokus perhatian pada materi pendidikan kesehatan (Melinda, Santi and Damayanti, 2018).

Metode demonstrasi adalah metode mengajar dengan cara memperagakan barang, kejadian, aturan, dan urutan melakukan suatu kegiatan, baik secara langsung maupun melalui penggunaan media pengajaran yang relevan dengan pokok bahasan atau materi yang sedang disajikan. Metode ini digunakan agar ibu menjadi lebih paham terhadap materi yang dijelaskan karena menggunakan alat peraga dan menggunakan media visualisasi yang dapat membantu ibu untuk lebih memahami (Rohendi, 2010)

Penelitian ini sesuai dengan yang dilakukan oleh (Melinda, Santi and Damayanti, 2018) yang menunjukan bahwa ada pengaruh pemberian metode demonstrasi, booklet, dan video terhadap perilaku ibu melakukan pijat bayi dengan nilai $p$-value 0,000 .

Manfaat penggunaan metode demonstrasi tersebut sesuai konsep pembelajaran menurut piramida pengalaman yang dituliskan oleh Edgar dale, bahwa orang belajar lebih dari $50 \%$ nya adalah dari apa yang telah di lihat dan di dengar. Sedangkan bila partisipan mengucapkan sambil mengerjakan sendiri suatu materi pendidikan kesehatan, maka ia akan mengingat $90 \%$ dari materi tersebut. Dimana keterampilan motorik dan sikap partisipan diasah (Aeni and Yuhandini, 2018)

Dari latar belakang di atas peneliti tertarik untuk melakukan penelitian tentang "Keefektifan Pendidikan Kesehatan Dengan Metode Demonstrasi Terhadap Keterampilan Ibu Dalam Pijat Bayi di Posyandu Serai Wangi Wilayah Kerja Pustu Pekan Arba Tembilahan Kota".

\section{METODE PENELITIAN}

Desain penelitian yang digunakan adalah studi pre eksperimen dengan pendekatan one group pretest posttest tanpa kelompok kontrol. Populasi pada penelitian ini adalah seluruh ibu yang mempunyai balita usia 0-1 tahun yang berjumlah $25 \mathrm{ibu}$ dengan bayinya di Posyandu Serai Wangi Wilayah Kerja Pustu Pekan Arba Tembilahan Kota. Jumlah sampel yang diambil adalah sebagian populasi yang berjumlah $21 \mathrm{ibu}$. Penelitian dilakukan pada tanggal 7 Desember 2020 dengan teknik sampling pada penelitian ini dengan simple random sampling.

Instrumen pada penelitian ini menggunakan lembar checklist yang digunakan untuk menilai kemampuan keterampilan ibu sebelum dan sesudah diberikan pendidikan kesehatan pijat bayi. Peneliti mengajukan persetujuan mengikuti penelitian pada responden. 
Tahap pertama peneliti melakukan pretest (menilai kemampuan psikomotor ibu melakukan pijat bayi sebelum diberi pendidikan kesehatan pijat bayi). Tahap kedua peneliti melakukan pendidikan kesehatan dengan demonstrasi pijat bayi menggunakan phantom. Tahap ketiga peneliti melakukan posttest (menilai kemampuan psikomotor ibu melakukan pijat bayi setelah diberi pendidikan kesehatan pijat bayi) ketiga tahapan penelitian dilakukan secara berurutan dihari yang sama. Analisis bivariate yang digunakan adalah uji $\mathrm{t}$ berpasangan (paired $t$ test) menggunakan program komputerisasi.

\section{HASIL}

Berdasarkan hasil penelitian didapatkan data sebagai berikut :

1. Karakteristik Ibu

Tabel 1

Distribusi frekuensi umur, pendidikan dan pekerjaan ibu di Posyandu Serai Wangi

Wilayah Kerja Pustu Pekan Arba Tembilahan Kota

\begin{tabular}{cccc}
\hline Karakter & Kategori & F & $\%$ \\
\hline Umur & $20-30$ tahun & 12 & 57,1 \\
\cline { 2 - 4 } & 31-40 tahun & 9 & 42,9 \\
\hline Pendidikan & $\begin{array}{c}\text { Dasar } \\
\text { (SD,SMP) }\end{array}$ & 9 & 42,9 \\
\cline { 2 - 4 } & $\begin{array}{c}\text { Menengah } \\
\text { (SMA) }\end{array}$ & 11 & 52,4 \\
\cline { 2 - 4 } & Tinggi (PT) & 1 & 4,8 \\
\hline Pekerjaan & IRT & 14 & 66,7 \\
\cline { 2 - 4 } & Swasta & 7 & 33,3 \\
\hline Total & & 21 & 100 \\
\hline
\end{tabular}

Berdasarkan tabel 1 dapat diketahui bahwa sebagian besar ibu berumur 20-30 tahun sebanyak 12 orang $(57,1 \%)$, berpendidikan menengah (SMA) sebanyak 11 orang $(52,4 \%)$ dan memiliki pekerjaan sebagai IRT sebanyak 14 orang $(66,7 \%)$.

2. Rata-rata keterampilan ibu dalam melakukan pijat bayi sebelum dilakukan pendidikan kesehatan

Tabel 2

Rata-rata keterampilan ibu dalam melakukan pijat bayi sebelum dilakukan pendidikan

kesehatan dengan menggunakan metode demonstrasi di Posyandu Serai Wangi Wilayah Kerja Pustu Pekan Arba Tembilahan Kota

\begin{tabular}{cccc}
\hline Variabel & N & Mean & SD \\
\hline $\begin{array}{c}\text { Sebelum } \\
\text { Penkes }\end{array}$ & 21 & 54,67 & 7,787 \\
\hline
\end{tabular}

Berdasarkan tabel 2 dapat diketahui bahwa rata-rata keterampilan ibu dalam melakukan pijat bayi sebelum dilakukan pendidikan kesehatan dengan metode demonstrasi didapatkan nilai rata-rata keterampilan ibu sebesar 54,67 dengan standar devisiasi 7,787.

3. Rata-rata keterampilan ibu dalam melakukan pijat bayi sesudah dilakukan pendidikan kesehatan

Tabel 3

Rata-rata keterampilan ibu dalam melakukan pijat bayi sesudah dilakukan pendidikan kesehatan dengan metode demonstrasi di Posyandu Serai Wangi Wilayah Kerja Pustu Pekan Arba Tembilahan Kota

\begin{tabular}{cccc}
\hline Variabel & N & Mean & SD \\
\hline $\begin{array}{c}\text { Sesudah } \\
\text { Penkes }\end{array}$ & 21 & 70,81 & 7,580 \\
\hline
\end{tabular}

Berdasarkan tabel 3 dapat diketahui bahwa rata-rata keterampilan ibu dalam melakukan pijat bayi sesudah dilakukan pendidikan kesehatan dengan metode demonstrasi didapatkan nilai rata-rata keterampilan ibu sebesar 70,81 dengan standar devisiasi 7,580.

\section{Analisis bivariat}

Tabel 4

Uji T Test Efektifitas Pendidikan Kesehatan Dengan Menggunakan Metode Demonstrasi Terhadap Keterampilan Ibu Dalam Melakukan Pijat Bayi di Posyandu Serai Wangi Wilayah Kerja Pustu Pekan Arba Tembilahan Kota

\begin{tabular}{llllllll}
\hline Variabel & $\mathrm{N}$ & Mean & $\mathrm{SD}$ & $\mathrm{t}$ & $\mathrm{P}$ & \multicolumn{2}{c}{$95 \% \mathrm{CI}$} \\
\cline { 6 - 8 } & & & & & $\begin{array}{c}\mathrm{va} \\
\text { lu }\end{array}$ & \multicolumn{1}{c}{$\begin{array}{c}\text { loww } \\
\text { er }\end{array}$} & upper \\
\hline Sebelum & 2 & $-16,143$ & 6,06 & - & 0, & - & - \\
penkes & 1 & & 9 & 12,1 & 00 & 18,90 & 13,38 \\
- & & & & 90 & 0 & 5 & 0 \\
$\begin{array}{l}\text { Sesudah } \\
\text { penkes }\end{array}$ & & & & & & & \\
\hline
\end{tabular}

Berdasarkan tabel 4 dapat diketahui 
dari 21 orang ibu rata-rata keterampilan ibu dalam melakukan pijat bayi sebelum dan sesudah dilakukan pendidikan kesehatan dengan menggunakan metode demonstrasi sebesar -16,143 dengan standar devisiasi 6,069 dan $p$ value $0,000(p<0,05)$ maka dapat disimpulkan bahwa pendidikan kesehatan dengan metode demonstrasi efektif terhadap peningkatan keterampilan ibu dalam melakukan pijat bayi

\section{PEMBAHASAN}

Berdasarkan tabel 1 dapat diketahui bahwa sebagian besar ibu berumur 20-30 tahun sebanyak 12 orang $(57,1 \%)$. Hasil ini menunjukkan bahwa sebagian ibu telah berada pada umur yang matang dan memiliki cukup pengalaman. Menurut (Bobak, Lowdermilk and Jense, 2012), pada umur remaja dapat mengalami kesulitan dalam menerima perubahan citra diri dan menyesuaikan peran-peran yang berhubungan dengan pijat bayi. Sedangkan kekhawatiran yang terkait dengan ibu yang berumur lebih dari 30 tahun semakin banyak muncul. Beberapa orang tua yang telah berumur merasa bahwa melakukan pijat bayi sangat susah untuk dilakukan.

Hasil penelitian ini sesuai dengan penelitian yang dilakukan (Pemayun and Winangsih, 2021) tentang gambaran pengetahun ibu tentang pijat bayi di desa dajan peken tabanan dengan hasil sebagian besar ibu memiliki usia 20-30 tahun $(93,3 \%)$, usia $30-40$ tahun $(6,1 \%)$ dan tidak ada yang berusia $>40$ tahun.

Pendidikan ibu sebagian besar yaitu menengah (SMA) sebanyak 11 orang $(52,4 \%)$. Menurut (Wawan and Dewi, 2011) faktor yang mempengaruhi tingkat pengetahuan dibagi menjadi dua yaitu 1). Faktor internal yang meliputi pendidikan, pekerjaan, umur; 2). Faktor eksternal yang meliputi lingkungan dan sosial budaya. Pendidikan mempengaruhi proses belajar makin tinggi tingkat pendidikan seseorang semakin mudah pula mereka menerima informasi dan akhirnya semakin banyak pula pengetahuan yang dimiliki. Sehingga ibu yang berpendidikan tinggi diharapkan lebih mampu menyerap informasi yang diberikan tentang kesehatan termasuk informasi tentang cara pengasuhan anak dengan baik.

Hasil ini sejalan dengan hasil penelitian (Safrina, 2013) yaitu ada pengaruh antara pendidikan dengan pengetahuan ibu tentang pijat bayi, dimana semakin tinggi pendidikan ibu maka semakin baik pengetahuan ibu tentang pijat bayi dan semakin rendah tingkat pendidikan ibu maka semakin rendah pengetahuan ibu.

Sesuai juga dengan pendapat (Machfoedz and Suryani, 2013) bahwa tingkat pendidikan merupakan satu variabel yang mempunyai pengaruh terhadap persepsi dari informasi yang datang untuk dipelajari.

Hasil penelitian sebanyak 14 orang $(66,7 \%)$ ibu bekerja sebagai IRT, ibu yang bekerja dirumah biasanya kurang dapat menambah pengetahuan dan penghasilan keluarga. Menurut (Notoatmodjo, 2012) ibu yang bekerja dapat menambah penghasilan keluarga untuk memenuhi kebutuhan termasuk untuk biaya kesehatan. Selain menambah penghasilan keluarga, pekerjaan juga meningkatkan akses informasi tentang kesehatan melalui interaksi di lingkungan kerja.

Hal ini sejalan dengan hasil penelitian (Safrina, 2013) yaitu ada pengaruh antara pekerjaan dengan pengetahuan ibu tentang pijat bayi, dimana Pekerjaan ibu tentunya sangat mempengaruhi interaksi sosial. Dalam proses interaksi sosial tentunya sering terjadi pertukaran informasi. Dalam hal ini sebagaian ibu-ibu mendapatkan informasi seputar pijat bayi dari temanteman dilingkungan pekerjaan, hal tersebut tentunya sangat mempengaruhi pengetahuan ibu tentang pijat bayi.

Berdasarkan hasil uji $T$ Test didapatkan rata-rata keterampilan ibu 
dalam melakukan pijat bayi sebelum dan sesudah dilakukan pendidikan kesehatan dengan menggunakan metode demonstrasi sebesar -16,143 dengan standar devisiasi 6,069 dan $p$ value 0,000 . Artinya pendidikan kesehatan dengan metode demonstrasi efektif terhadap peningkatan ketrampilan ibu dalam melakukan pijat bayi.

Hasil penelitian ini didukung oleh penelitian (Sundari, 2018) yang mengatakan bahwa pendidikan kesehatan dengan menggunakan metode demonstrasi efektif terhadap keterampilan dukun dalam pijat bayi dengan nilai $\mathrm{t}$ hitung $(13,298)>\mathrm{t}$ tabel $(2,145)$,

Menurut (Azwar, 2020), penyuluhan kesehatan merupakan kegiatan pendidikan kesehatan yang dilakukan dengan cara menyebar pesan, menanamkan keyakinan sehingga masyarakat tidak hanya sadar, tahu, dan mengerti tetapi juga mau melakukan tindakan yang ada kaitannya dengan kesehatan.

Peningkatan keterampilan ibu dalam pijat bayi kemungkinan besar dipengaruhi oleh pemberian informasi, metode yang digunakan dan motivasi. Pemberian informasi yang telah diperoleh saat pendidikan kesehatan tentang keterampilan pijat bayi oleh bidan. Pemberian informasi sangat penting dilakukan karena pijat bayi mempunyai banyak manfaat. Menurut (Roesli, 2015a) bahwa manfaat pijat bayi adalah meningkatkan berat badan,meningkatkan pertumbuhan, meningkatkan daya tahan tubuh, meningkatkan konsentrasi bayidan membuat bayi tertidur lelap, membina ikatan kasih sayang orang tua dan anak sertameningkatkan produksi ASI.

Selain itu penggunaan metode juga mempengaruhi keberhasilan pada pendidikankesehatan, dimana pada pendidikan kesehatan ini menggunakan metode demonstrasi yangmemiliki ciri memperagakan materi pendidikan kesehatan secara visual. Hal ini sesuai denganpendapat (Nursalam, 2013) bahwa pendidikan kesehatan akan berhasil bila mengggunakanstrategi dengan mempelajari karakteristik belajar orang dewasa.

Penelitian yang menyatakan adanya pengaruh penggunaan metode demonstrasi adalah penelitian (Astuti and Surasmi, 2016) yang berjudul pegaruh penyuluhan kesehatan tentang menyusui dengan metode demonstrasi terhadap kemampuan ibu menyusui di rumah bersalin wilayah Banjarsari Surakarta dengan hasil $p$-value 0,000 yang berarti terjadi peningkatan yang signifikan antara kemampuan ibu menyusui sebelum dan sesudah dilakukan penyuluhan

Hasil penelitian yang dilakukan (Oktobriariani, 2010) didapatkan hasil bahwa kemampuan praktik pijat bayi seorang ibu sesudah diberi pendidikan kesehatan tentang pijat bayi lebih baik, hal ini didukung oleh metode yang dipakai dalam memberikan penyuluhan ini menggunakan metode ceramah dan mendemonstrasikan atau mempraktikkan secara langsung langkah memijat bayi yang baik dan benar.

Disamping itu, ibu sangat antusias mendengarkan dan memperhatikan materi tentang pijat bayi saat pendidikan kesehatan berlangsung, hal ini sesuai dengan pendapat (Machfoedz and Suryani, 2013) bahwa motivasi merupakan salah satu faktor yang mempengaruhipendidikan kesehatan apabila pendidik dan peserta didik samasama memiliki motivasi yangtinggi terhadap materi yang sedang dipelajari tentu hasilnya akan baik.

Hal ini dapat dijelaskan bahwa pendidikan kesehatan dengan metode demonstrasi dapat meningkatkan pengetahuan ibu tentang cara melakukan pijat bayi, pengetahuan yang dimiliki tersebut akan ditelaah lebih dalam yang akan menentukan sikap dan dapat meningkatkan keterampilan melakukan pijat bayi. 


\section{SIMPULAN}

Berdasarkan hasil penelitian dan pembahasan terhadap 21 orang ibu tentang keefektifan pendidikan kesehatan dengan menggunakan metode demonstrasi terhadap keterampilan ibu dalam pijat bayi di Posyandu Serai Wangi Wilayah Kerja Pustu Pekan Arba Tembilahan Kota maka dapat disimpulkan:

1. Rata-rata keterampilan ibu dalam melakukan pijat bayi sebelum dilakukan pendidikan kesehatan dengan metode demonstrasi sebesar 54,67 dan sesudah dilakukan pendidikan kesehatan dengan metode demonstrasi didapatkan nilai rata-rata keterampilan ibu sebesar 70,81

2. Rata-rata keterampilan ibu dalam melakukan pijat bayi sebelum dan sesudah dilakukan pendidikan kesehatan dengan metode demonstrasi sebesar -16,143 dan $p$ value 0,000 yang berarti pendidikan kesehatan dengan menggunakan metode demonstrasi efektif terhadap peningkatan ketrampilan ibu dalam melakukan pijat bayi

\section{UCAPANTERIMAKASIH}

Saya ucapkan terimakasih kepada Direktur dan UPPM Akademi Kebidanan Husada Gemilang serta Kepala Puskesmas Pembantu Pekan Arba yang telah membantu penulis dalam menyelesaikan penelitian ini.

\section{DAFTAR PUSTAKA}

Aeni, N. and Yuhandini, D. S. (2018) 'Pengaruh Pendidikan Kesehatan Dengan Media Video Dan Metode Demonstrasi Terhadap Pengetahuan SADARI', Care : Jurnal Ilmiah Ilmu Kesehatan, 6(2), p. 162. doi: 10.33366/cr.v6i2.929.

Ambasari, M. H., Anggarini, S. and Nugraheni, A. (2017) 'The Effect of Infant Massage Counseling on Infant Massage Practice by Mothers in Tugu Village, Jumantono Sub-District, Karanganyar Regency', Journal of Health Science and
Prevention, 1(2), pp. 73-78. doi: 10.29080/jhsp.v1i2.78.

Andriani, Merryana and Wijatmadi, B. (2012) Pengantar Gizi Masyarakat. Jakarta: Kencana.

Astuti, S. L. D. and Surasmi, A. (2016) 'Pengaruh Penyuluhan Kesehatan Tentang Menyusui Dengan Metode Demonstrasi Terhadap Kemampuan Ibu Menyusui Di Rumah Bersalin Wilayah Banjarsari Surakarta', Interest: Jurnal Ilmu Kesehatan, 5(2). doi: 10.37341/interest.v5i2.57.

Azwar, S. (2020) Sikap Manusia: Teori dan Pengukurannya (edisi 2). 2nd edn. Yogyakarta: Pustaka Pelajar.

Bobak, Lowdermilk and Jense (2012) Buku Ajar Keperawatan Maternitas. Jakarta.

Handayani, E. Y. and Wulandari, S. (2021) 'Hubungan Pendidikan Kesehatan Tentang Pijat Bayi Terhadap Pengetahuan Ibu Di Desa Kepenuhan Hulu Kabupaten Rokan Hulu’, 03(03), p. 11.

Machfoedz, I. and Suryani, E. (2013) Pendidikan Kesehatan Bagian Dari Promosi Kesehatan. Yogyakarta: F Tranaya.

Marmi and Rahardjo, K. (2012) Asuhan Neonatus, Bayi, Balita Dan Anak Prasekolah. Yogyakarta: Pustaka Pelajar.

Melinda, P., Santi, E. and Damayanti, E. A. F. (2018) 'Metode Demonstrasi, Booklet, Dan Video Terhadap Perilaku Ibu Melakukan Pijat Bayi', p. 6.

Notoatmodjo, S. (2012) Promosi Kesehatan dan Ilmu Perilaku. Jakarta: Rineka Cipta.

Nursalam (2013) Metodologi Penelitian Ilmu Keperawatan: Pendekatan Praktis. 4th edn. Jakarta: Salemba Medika.

Oktobriariani, R. R. (2010) 'Program Studi Div Kebidanan Fakultas Kedokteran Universitas Sebelas Maret Surakarta', p. 58.

Pemayun, C. I. M. and Winangsih, R. (2021) 'Gambaran Pengetahuan Ibu Tentang Pijat Bayi Di Desa Dajan Peken Tabanan', 4, p. 6.

Rochmah (2012) Panduan Belajar: Asuhan Neonatus, Bayi,\& Balita. Jakarta: EGC.

Roesli (2015a) Pedoman Pijat Bayi. Jakarta: Puspa Swara.

Roesli (2015b) Pedoman Pijat Bayi Edisi 
Revisi. Jakarta: PT Trubus Agriwidya.

Rohendi, D. (2010) 'Efektivitas Metode Pembelajaran Demonstrasi Terhadap Peningkatan Hasil Belajar Siswa Kelas X Pada Mata Pelajaran Keterampilan Komputer dan Pengelolaan Informasi Di Sekolah Menengah Kejuruan', Jurnal Pendidikan Informasi Dan Komunikasi, 3(1), pp. 16-18.

Safrina (2013) Faktor-Faktor Yang Mempengaruhi Pengetahuan Ibu Tentang Pijat Bayi Di BPS Jauniwati Indrapuri Kabupaten Aceh Besar. Program studi diploma kebidanan sekolah tinggi ilmu kesehatan u'budiyah.

Sulistiani, A. and Wijayanti, T. (2020) 'Keterampilan Ibu Dalam Melakukan Pijat Bayi', Jurnal Kebidanan, (01), p. 10.

Sundari (2018) 'Keefektifan Pendidikan Kesehatan Dengan Menggunakan Metode Demonstrasi Terhadap Keterampilan Dukun Dalam Pijat Bayi Di Wilayah Kerja Puskesmas Babadan Kabupaten Ponorogo', GLOBAL HEALTH SCIENCE, 3, pp. 358-365.

Vicente, S., Veríssimo, M. and Diniz, E. (2017) 'Infant Behavior and Development Infant massage improves attitudes toward childbearing, maternal satisfaction and pleasure in parenting. Infant Behavior and Development', 49, pp. 114-119.

Wawan, A. and Dewi, M. (2011) Teori dan Pengukuran Pengetahuan, Sikap, dan Perilaku Manusia. II. Yogyakarta: Nuha Medika. 